Original Article

\title{
Ingenuity for enabling the habituation of pelvic floor muscle training
}

\author{
Akiko Mori, $\mathrm{PhD}^{1)^{*}}$, Masayoshi Kakiuchi, $\mathrm{MS}^{2)}$, Emi Matsumoto, $\mathrm{MS}^{3)}$, \\ SonOKo NozAKI, MD, $\mathrm{PhD}^{4)}$ \\ 1) Department of Physical Therapy School of Rehabilitation, Hyogo University of Health Sciences: \\ 1-3-6 Minatojima, Chuo-ku, Kobe 650-8530, Japan \\ 2) Department of Rehabilitation, Nishikobe Medical Center, Japan \\ 3) Department of Rehabilitation Medicine, Kansai Electric Power Hospital, Japan \\ 4) Department of Neurology, Kansai Rosai Hospital, Japan
}

\begin{abstract}
Purpose] To clarify factors contributing to habituation of pelvic floor muscle training (PFMT) for urinary incontinence. [Subjects and Methods] We included 13 healthy females and examined diurnal and nocturnal urination frequency at initial program participation and at 3 months. The survey used the International Consultation on Incontinence Questionnaire-Short Form (ICIQ-SF), a 10-level self-assessment of anxiety associated with urinary incontinence, and a 10-level self-evaluation of PFMT understanding and skill acquisition. We evaluated PFMT practice at home and postures that facilitated PFMT. The practice of PFMT at home was surveyed during a 3-month period. [Results] Compared to baseline, the level of skill acquisition assessed by the ICIQ-SF and PFMT according to the 10-level self-evaluation improved significantly at 3 months. The rate of PFMT sessions performed at home per week was high. The number of times PFMT was performed per day was positively correlated with level of understanding and acquisition of skills pertaining to PFMT, according to the 10-level self-assessment. [Conclusion] By incorporating behavior modification techniques appropriate for urinary incontinence and by increasing the level of understanding regarding incontinence and PFMT, as well as the level of skill acquisition, self-efficacy increased. This may have motivated habituation of PFMT.

Key words: Urinary incontinence, Pelvic floor muscle training, Regular habits
\end{abstract}

(This article was submitted Feb. 7, 2017, and was accepted May 9, 2017)

\section{INTRODUCTION}

Urinary incontinence (UI) results from age-related weakness of the pelvic floor muscles, childbirth, and obesity; it affects 30 to $40 \%$ of females. Among them, $80 \%$ have stress urinary incontinence (SUI) symptoms ${ }^{1,2}$ ). In a Cochrane Systematic Review, pelvic floor muscle training $(\mathrm{PFMT})^{3,4)}$ was recommended as the first choice of treatment in SUI ${ }^{5}$, and its effectiveness has been reported by a number of authors ${ }^{5,6}$. Thus, the effectiveness of PFMT in the treatment of UI has been validated, but in clinical settings, guidance and coaching regarding PFMT have mostly been carried out by handing out brochures or by providing oral guidance regarding gymnastics, therefore acquisition of PFMT skill has been difficult ${ }^{7}$. In addition, although it takes approximately 3 months until the effects of PFMT start to appear ${ }^{5)}$, there are difficulties where PFMT cannot actually be performed continuously ${ }^{7}$. PFMT can only be expected to be effective once the patients themselves have a correct understanding of PFMT and practice it continuously; this requires an effective training program. However, our search results have not detected any previous study that examined the factors needed for the habituation of PFMT.

The purpose of this study was to clarify the factors necessary for the habituation of PFMT that are highly effective for SUI.

*Corresponding author. Akiko Mori (E-mail: moakiko@huhs.ac.jp)

(C2017 The Society of Physical Therapy Science. Published by IPEC Inc.

(c) $(-)$ This is an open-access article distributed under the terms of the Creative Commons Attribution Non-Commercial No Deriva-

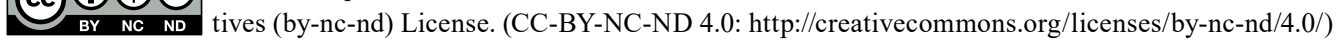


Table 1. Types of pelvic floor muscle training (PFMT)

\begin{tabular}{ll}
\hline Type & Method \\
\hline (1) Supine & PFMT in supine position \\
(2) Supine + Ball & PFMT while holding the ball between the knee in the supine position \\
(3) Sitting & PFMT in sitting position \\
(4) Sitting + Ball & PFMT while holding the ball in the knee in the sitting position \\
(5) Standing [Static] & PFMT in standing position \\
(6) Standing [Squat] & PFMT while holding a squat \\
\hline
\end{tabular}

\section{SUBJECTS AND METHODS}

This project was carried out as part of a program aimed at habituation of PFMT. Among the 18 community-dwelling healthy females who applied for participation, the study was conducted on 13 participants (age: $66.6 \pm 7.8$ years, height: $155.5 \pm 7.5 \mathrm{~cm}$, weight: $53.6 \pm 7.9 \mathrm{~kg}$, body mass index: $22.1 \pm 2.7$ ) following application of the exclusion criteria. The exclusion criteria were as follows: a history of urological and gynecological diseases or a history of surgery and receiving medical treatment at the time of the study, having cardiovascular diseases and receiving medical treatment at the time of the study, participation being judged inappropriate according to a physician, and inability to participate continuously in the study.

The content of the program consisted of lectures aimed at deepening knowledge regarding the symptoms and causes of UI, the muscles and constituents of the pelvic floor, and the purposes and effects of PFMT. During the lectures, the participants were instructed to use a pelvic floor model, to fit their own bodies to the model, and to imagine the muscles that affected the pelvic organs. After the lectures were over, a practice session was carried out by two physical therapists to train the participants in practical skills. A total of 6 types of PFMT were adopted, in two of each of the following postures: supine position, sitting position, and standing position (Table 1). The participants were instructed to continue performing PFMT for 3 months, especially at home. In addition, a review table was distributed so that the participants could continue performing PFMT at home; the participants were instructed to record the number of times they performed PFMT each day.

Follow-up was performed to confirm whether the PFMT was still being practiced correctly at 1 and 2 months after the initial exercise. For participants who were unable to practice PFMT correctly, teaching was repeated in order for the participants to re-acquire practical skills. Three months after the initial PFMT, a questionnaire regarding the survey items was sent by mail to the participants, who were instructed to fill it out and send it back by mail.

Information on the following survey items was collected as basic data: age, height, body weight, body mass index, personal medical history, history of childbirth, number of deliveries (parity), and the presence or absence of UI. Surveys were performed at the time of the first PFMT and at 3 months, using questionnaires for the following survey items: diurnal and nocturnal urination frequency, International Consultation on Incontinence Questionnaire-Short Form (ICIQ-SF), 10-level self-assessment of anxiety associated with UI (0: stable, 10: anxious), level of understanding of PFMT according to a 10-level self-assessment (0: no understood, 10: understood enough), level of skill acquisition pertaining to PFMT according to a 10-level self-assessment (0: no acquired, 10: enough acquired), frequency of PFMT practice at home, and postures that facilitated PFMT. Further, the number of times PFMT was performed at home during a 3-month period and participant impressions after participating in the program were also surveyed.

In the statistical analysis, the results from each survey item at the time of initial PFMT were compared with those found at 3 months by using statistical software R 2.8.1. To compare differences in mean values, the Shapiro-Wilk normality test was carried out; when a normal distribution was found, a paired t-test was performed. When the findings showed no normal distribution, the Wilcoxon rank-sum test was performed. In addition, the association between the number of times PFMT was performed per day and the survey items at 3 months was analyzed by using Spearman's rank correlation coefficient. In the statistical study, $\mathrm{p}$ values $<0.05$ were considered significant.

This study was carried out with the approval of Hyogo University of Health Sciences Ethics Committee No. 14001.

Informed consent was obtained from the participants after they were provided verbal and written explanations regarding the purpose of the study, its significance, the protection of personal information, study participation based on free will, freedom to withdraw consent, and the publication of the results.

\section{RESULTS}

Table 2 shows the characteristics of 13 participants; Table 3 shows findings for each survey item at the time of initial participation in the program and after 3 months. The daytime urination frequency was $7.7 \pm 2.1$ times at initial participation and $8.0 \pm 1.2$ times after 3 months. Nighttime urination frequency was $0.7 \pm 0.6$ times at initial participation and $0.8 \pm 0.7$ times after 3 months; no significant difference was found between diurnal and nocturnal frequencies. The ICIQ-SF was $3.2 \pm$ 2.4 at the time of initial measurements and $1.6 \pm 2.2$ after 3 months; a significant difference was found ( $\mathrm{p}=0.04)$. Comparisons between individuals also showed that the scores had improved in most participants. The 10-level self-assessment of anxiety 
Table 2. Characteristics of the participants

\begin{tabular}{lr}
\hline Participants & \\
\hline Age (years) & $66.6 \pm 7.8$ \\
Height $(\mathrm{cm})$ & $155.5 \pm 7.5$ \\
Weight $(\mathrm{kg})$ & $53.6 \pm 7.9$ \\
BMI $\left(\mathrm{kg} / \mathrm{m}^{2}\right)$ & $22.1 \pm 2.7$ \\
History of childbirth (persons) (\%) & $8(61.5)$ \\
Number of deliveries (parity) (times) & $2.5 \pm 1.1$ \\
Incontinence (yes $/$ no) & $6 / 7$ \\
\hline
\end{tabular}

$\mathrm{N}=13$, Mean $\pm \mathrm{SD}$

Table 3. Comparison between measurement items at the time of initial measurement and after 3 months

\begin{tabular}{llcc}
\hline & & Initial & 3 months later \\
\hline Frequency of urination (times) & Daytime & $7.7 \pm 2.1$ & $8.0 \pm 1.2$ \\
& Nighttime & $0.7 \pm 0.6$ & $0.8 \pm 0.7$ \\
ICIQ-SF & & $3.2 \pm 2.4$ & $1.6 \pm 2.2^{*}$ \\
Anxiety & & $1.8 \pm 1.3$ & $1.1 \pm 1.2$ \\
Understanding at PFMT & $8.5 \pm 1.7$ & $9.2 \pm 0.9$ \\
Proficiency at PFMT & $8.1 \pm 2.0$ & $9.0 \pm 1.2^{*}$ \\
Best position (persons) & supine: 8 & supine: 11 \\
Exercise dates (days/week) (persons) & \multicolumn{2}{c}{$6-7$ days/week: 12} \\
& \multicolumn{2}{c}{4 days/week: 1}
\end{tabular}

$\mathrm{N}=13$, Mean $\pm \mathrm{SD},{ }^{*} \mathrm{p}<0.05$.

PFMT: pelvic floor muscle training; ICIQ-SF: International Consultation on Incontinence Questionnaire-Short Form

Table 4. Frequency of pelvic floor muscle training (PFMT): coefficient of correlation with survey items after 3 months

\begin{tabular}{lc}
\hline & 3 months later \\
\hline ICIQ-SF & 0.09 \\
Anxiety & -0.01 \\
Understanding at PFMT & $0.70^{*}$ \\
Proficiency at PFMT & $0.58^{* *}$ \\
\hline $\mathrm{N}=13, * \mathrm{p}<0.01, * * \mathrm{p}<0.05$ &
\end{tabular}

in association with UI showed scores of $1.8 \pm 1.3$ at the time of initial measurement and $1.1 \pm 1.2$ after 3 months; comparisons between individuals showed a decrease or increase in anxiety, but no significant difference was found. The PFMT level of understanding according to a 10-level self-assessment showed scores of $8.5 \pm 1.7$ at the time of initial measurements and $9.2 \pm$ 0.9 after 3 months; no significant difference was found. In all participants, the self-assessed level of understanding was either maintained or increased at 3 months later. The self-assessed level of acquisition of skills pertaining to PFMT showed scores of $8.1 \pm 2.0$ at the time of initial measurements and $9.0 \pm 1.2$ at 3 months; a significant difference was found ( $\mathrm{p}=0.01)$. In all participants, the self-assessed level of acquisition of skills was either maintained or increased after 3 months. At the time of initial measurement and after 3 months, the postures that facilitated PFMT were supine position. In detail, 8 participants responded that the supine position facilitated PFMT at the time of initial measurement; the number of participants with this response increased to 11 at 3 months later. Twelve participants performed PFMT at home 6 to 7 days a week, and 1 performed PFMT at home 4 to 5 days a week, showing a high rate of compliance with instructions. In addition, the frequency of PFMT performed at home during the 3-month program was $23.6 \pm 8.0$ times a day.

On the basis of the number of times PFMT was performed per day, a positive correlation was found between the level of understanding of PFMT according to the 10 -level self-assessment $(\mathrm{p}=0.008, \mathrm{r}=0.70)$ and the self-assessed level of acquisition of skills $(\mathrm{p}=0.04, \mathrm{r}=0.58)$ (Table 4). 


\section{DISCUSSION}

ICIQ-SF improved significantly after 3 months compared to scores at the time of initial measurement $(\mathrm{p}=0.04)$. The acquisition skill level according to a 10-level self-assessment of PFMT improved significantly after 3 months compared to the level at the time of initial measurement $(\mathrm{p}=0.01)$. The amount of PFMT performed at home per week showed a high continuation rate and, in terms of the number of times PFMT was performed per day, a positive correlation was found between the level of understanding of PFMT according to a 10-level self-assessment $(\mathrm{p}=0.008, \mathrm{r}=0.70)$ and the self-assessed level of acquisition of skills $(\mathrm{p}=0.04, \mathrm{r}=0.58)$.

As seen in the program that was conducted in our study, lectures that provided participants with knowledge regarding UI and the purpose of PFMT as well as its effect, PFMT practice in small groups, and follow-up on a regular basis for 3 months may have led to a significant improvement in the level of skill acquisition pertaining to ICIQ-SF and PFMT according to a 10-level self-assessment. Feedback from the participants included comments such as the following: "receiving actual guidance on practical skills has allowed me to understand how to do the training correctly", and "suffering from UI really bothered me, but now my anxiety has been relieved". Although a comparison between the frequency of urination before and after the program showed no significant difference, some participants indicated that they had a successful practical experience, as the comments included the following: "the time intervals between toilet visits have become longer", or "I have acquired the ability to control myself even when I feel as though urine is about to leak out". As the participants were given an opportunity to learn how to contract pelvic floor muscles, the muscles may have been continuously affected by increased self-efficacy and physical changes due to exercise ${ }^{8,9}$. A series of programs like these used in our study may have improved self-efficacy, and may have led to motivation to perform PFMT as a habit.

Regarding PFMT performance at home, the participants were instructed to exercise as much as and whenever possible by using methods that made it easier to perform PFMT; instructions were given without showing the type of exercise or the frequency at which it was to be performed. As a result, the psychological burden related to the fact of practicing was alleviated, and the participants' own motivation was stimulated, leading to a high rate of compliance with instructions. In addition, in this study, the participants were instructed to use a review table to record the number of trainings performed each day. With the review table, blackening the spaces indicating the number of trainings performed allowed conversion of the data into graphs; at a glance, the participants themselves were able to review the increase or decrease in the daily number of times the trainings were performed. Among the various theories and models for exercise coaching, the trans-theoretical model ${ }^{10)}$ has been actively applied to various kinds of teaching methods in health education ${ }^{11-13)}$. In the stages of behavioral change, which is its core concept, guidance is carried out depending on 5 stages that differ on the basis of readiness for behavioral change; its purpose is to promote effective behavior modification ${ }^{10}$. Given that our study was conducted on participants who showed interest in UI and PFMT and who actually desired guidance, most of the subjects were in the preparatory phase of behavior modification stages. At this stage, "the amount of exercise is increased progressively until the targeted amount is reached"; as stage-compatible behavior modification techniques, methods such as self-monitoring (self-recording of behavior) are recommended in the preparatory phase ${ }^{14,15}$. A method known as "shaping" consists of dividing the target behavior into several small steps in a phased manner (the small-step method), and of shaping behaviors by starting with those that have achievable results ${ }^{16}$. In our study, using the review table to assess the results of training allowed for a natural setting to target the muscles and train for the next day and later; the recommendations of PFMT that were easy to carry out, as well as the recommendation to train as much as and whenever possible, may have led to behavior modification based on the concept of shaping. Therefore, the findings suggested that carrying out the program by adopting techniques incorporating these behavior modification-promoting factors was important in contributing to the habituation of PFMT.

Additionally, the number of times PFMT was performed per day showed a positive correlation between the self-assessed level of PFMT understanding $(\mathrm{p}=0.008, \mathrm{r}=0.70)$ and the self-assessed level of skill acquisition pertaining to PFMT $(\mathrm{p}=0.04$, $\mathrm{r}=0.58)$ at 3 months. In a previous study of the long term effects of PFMT treatment that used the contents of a health education program for women suffering from UI, the authors stated that optimization of adherence was a contributing factor to the success of health education programs ${ }^{17}$ ). In the program that was carried out in our study, lectures were given with the aim to deepen understanding of UI and pelvic floor anatomy, as well as improve knowledge pertaining to the purposes and effects of PFMT. In addition, during the lectures, the participants were instructed to utilize pelvic floor models and to visualize the pelvic organs. This might be the reason why the participants became self-confident in performing PFMT, and also the reason why the frequency of PFMT showed a positive correlation between self-assessed level of understanding of PFMT and selfassessed level of skill acquisition pertaining to PFMT. In other words, the use of behavior modification techniques adapted to each stage, as well as the improved level of understanding and acquisition of skills pertaining to PFMT, may have helped optimize adherence. In this study, there was no correlation between the number of times PFMT was performed and ICIQ-SF. This is probably because the subjects of this study were those with no UI or more mildly UI.

A limitation of our study was that it was conducted on a group of participants who were interested in UI and PFMT. Those who applied for participation of their own accord were more inclined to maintain their motivation for the fixed period. Future research involving comparative studies may need to use randomization in order to specifically elucidate the adherencerelated aspects of this study. 
In addition, it would be advantageous to take accurate measurements of pelvic floor muscle volume for the study period. This objective indicator can reduce bias even if obsequious or vague comments are contained in participant self-assessments. Moreover using a double blind experiment would be the operative method of judging the effects of habituation for PFMT.

In any event, it is necessary to raise public awareness for a better understanding of measures against UI. For instance, this study is an effective clarification for habituation of PFMT.

\section{ACKNOWLEDGEMENTS}

This study received a research grant from the Furukawa Medical \& Welfare Foundation (second research grant for fiscal year 2014). The authors wish to thank the Akiko Inaba MS (Department of rehabilitation, Morinomiya Hospital) for their invaluable contribution to this study.

\section{REFERENCES}

1) Hunskaar S, Lose G, Sykes D, et al.: The prevalence of urinary incontinence in women in four European countries. BJU Int, 2004, 93: 324-330. [Medline] [CrossRef]

2) Kinchen KS, Burgio K, Diokno AC, et al.: Factors associated with women's decisions to seek treatment for urinary incontinence. J Womens Health (Larchmt), 2003, 12: 687-698. [Medline] [CrossRef]

3) Kegel AH: Progressive resistance exercise in the functional restoration of the perineal muscles. Am J Obstet Gynecol, 1948, 56: 238-248. [Medline] [CrossRef]

4) Kegel AH: Physiologic therapy for urinary stress incontinence. J Am Med Assoc, 1951, 146: 915-917. [Medline] [CrossRef]

5) Dumoulin C, Hay-Smith J: Pelvic floor muscle training versus no treatment, or inactive control treatments, for urinary incontinence in women. Cochrane Database Syst Rev, 2010, 20: CD005654. [Medline]

6) Hirakawa T, Suzuki S, Kato K, et al.: Randomized controlled trial of pelvic floor muscle training with or without biofeedback for urinary incontinence. Int Urogynecol J Pelvic Floor Dysfunct, 2013, 24: 1347-1354. [Medline] [CrossRef]

7) Bø K, Mørkved S: Pelvic floor and exercise science. In: Bø K, Berghmans B, Mørkved S, Van Kampen M (eds.), Evidence-based physical therapy for the pelvic floor. Philadelphia: Elsevier, 2007, pp 111-130.

8) Alewijnse D, Mesters I, Metsemakers J, et al.: Predictors of intention to adhere to physiotherapy among women with urinary incontinence. Health Educ Res, 2001, 16: 173-186. [Medline] [CrossRef]

9) Messer KL, Hines SH, Raghunathan TE, et al.: Self-efficacy as a predictor to PFMT adherence in a prevention of urinary incontinence clinical trial. Health Educ Behav, 2007, 34: 942-952. [Medline] [CrossRef]

10) Prochaska JO, DeClemente CC: Transtheoretical therapy: toward a more integrative model of change. Psychotherapy, 1982, 19: 276-288. [CrossRef]

11) Prochaska JO, Marcus BH: The transtheoretical model:applications to exercise. In:Advances in exercise adherence (ed. by Dishman RK).Champaign: Human Kinetics, 1994, pp 61-180.

12) Marcus BH, Simkin LR: The transtheoretical model: applications to exercise behavior. Med Sci Sports Exerc, 1994, 26: 1400-1404. [Medline] [CrossRef]

13) Hutchison AJ, Breckon JD, Johnston LH: Physical activity behavior change interventions based on the transtheoretical model: a systematic review. Health Educ Behav, 2009, 36: 829-845. [Medline] [CrossRef]

14) Prochaska JO, DiClemente CC, Norcross JC: In search of how people change. Applications to addictive behaviors. Am Psychol, 1992, 47: 1102-1114. [Medline] [CrossRef]

15) Inoue S, Odagiri $\mathrm{Y}$, Wakui S, et al.: Randomized controlled trial to evaluate the effect of a physical activity intervention program based on behavioral medicine. J Tokyo Med Univ, 2003, 61: 154-165.

16) Woldag H, Stupka K, Hummelsheim H: Repetitive training of complex hand and arm movements with shaping is beneficial for motor improvement in patients after stroke. J Rehabil Med, 2010, 42: 582-587. [Medline] [CrossRef]

17) Alewijnse D, Metsemakers JF, Mesters IE, et al.: Effectiveness of pelvic floor muscle exercise therapy supplemented with a health education program to promote long-term adherence among women with urinary incontinence. Neurourol Urodyn, 2003, 22: 284-295. [Medline] [CrossRef] 